\title{
A Systematic Review of Refugee Women's Reproductive Health
}

\author{
Anita J. Gagnon, Lisa Merry, and Cathlyn Robinson
}

\begin{abstract}
Resettling refugee women may be at greater risk than other women for several harmful reproductive health outcomes as a result of their migration experience. The objective of this study was to determine differences in reproductive health status between refugee women in countries of resettlement and non-refugee counterparts. A systematic review of the literature culled from five electronic databases and web searching of international agencies and academic centres focusing on refugees was conducted. Of the forty-one high quality studies identified, fourteen looked at refugees exclusively; only nine of the fourteen focused on the reproductive health of refugees; six of the nine directly compared refugee to non-refugee women's health. There is a paucity of populationbased data to support or refute claims of greater reproductive health risks for resettling refugee women.
\end{abstract}

\section{Résumé}

Les femmes réfugiées en situation de réétablissement pourraient bien être plus susceptibles que d'autres femmes de souffrir d'un certain nombre de conséquences néfastes en matière de santé génésique suite à l'expérience de la migration. Le but de cette étude était de cerner les différences entre le niveau de santé génésique des femmes réfugiées dans les pays de réétablissement et leurs congénères non-réfugiées. Pour ce faire, un examen systématique de la littérature provenant de cinq bases de données électroniques a été entrepris, ainsi que des recherches sur le Web d'agences et de centres académiques internationaux. Des 41 études de haut niveau identifiées, seules 9 de ces études se concentraient sur la santé génésique des réfugiées; 6 de ces 9 études effectuaient une comparaison directe entre la santé des réfugiées et celle des non-réfugiées. Il existe en fait un manque de données démographiques qui permettraient de soutenir ou de rejeter l'affirmation selon laquelle les risques sont accrus en matière de santé génésique chez les femmes réfugiées en cours de réétablissement.

\section{Introduction}

7 here are currently fifteen million refugees and asylumseekers worldwide, ${ }^{1}$ a percentage of whom will resettle in host countries. The health of resettling refugees is not well known since health data are rarely reported for refugees separate from all immigrants combined. Refugees, individuals forced from their homeland and unable to return for a period of time due to socio-political instability (paraphrased from $\mathrm{UNHCR}^{2}$ ), and asylum seekers arriving in resettlement countries are thought to be at greater risk than the general population for several harmful health outcomes as a result of their migration history. Anecdotal reports from professionals suggest that childbearing and other aspects of reproductive health add an additional burden on female refugees, which places them in a particularly disadvantaged position. These suppositions have not been systematically examined.

Reports would suggest that screening and care provided to resettling refugees is anything but systematic. ${ }^{3}$ Policy makers and program planners, however, generally see knowledge of health "events" (including illness episodes and health/social services use) as required for optimal health planning. ${ }^{.}$The extent and nature of health "events" and their determinants in resettling refugee women and their infants becomes even more relevant when the role of 
development from birth to six months of life on future health outcomes is considered. ${ }^{5}$

\section{Review of the Literature}

\section{Refugee Women's Reproductive Health}

Prior to Resettlement

Refugee women experience several challenges to their health. Published review articles and case studies describe the experience of refugees in transit or in camps. The issues considered can be grouped into five broad categories: (1) fertility regulation, (2) sexually transmitted infections, (3) sex and gender-based violence, (4) pregnancy and childbirth, and (5) health services availability and use.

There are differing opinions of the effects of migration on fertility and family planning. ${ }^{6}$ One suggests that forced migration increases fertility as refugees satisfy their desire to repopulate, in order to replace deceased children or soldiers and as migration produces a healthier, more stable environment (for example, in some camp situations) with improved health care services and nutrition. The opposing opinion suggests that migration decreases the fertility rate of refugees because of perceived uncertainty of the future, economic instability, and marital separation. Fertility rates have also been found to vary with knowledge and availability of contraception. In sum, there are no known common fertility patterns of refugees.

Refugee women appear to be at greater risk than other women for sexually transmitted infections (STIs), including human immunodeficiency virus (HIV), for a variety of reasons. ${ }^{7}$ Migration often occurs without the accompaniment of spouses, thereby increasing the likelihood of sexual activity outside stable relationships. Military operations have been found to be associated with an increase in STI transmission and many refugees are fleeing war-torn areas or must travel through or encamp in those areas. Economic disruption may require refugee women to be involved in sexual activity to acquire food or other goods for themselves or their children. Psychological stresses, including the need for protection from soldiers or men living in or near the camps, may also lead to the granting of sexual favours. Men entrusted to ensure the travel of refugee women to a safe haven may demand sexual favors. Migration appears to increase the incidence of sexual and gender-based violence (SGBV; e.g., rape, forced impregnation, and other forms of violence), which in turn promotes the spread of STIs.

The use of SGBV by one group to oppress another has long been in existence in times of war. Incidence is difficult to estimate since it is grossly under-reported. The use of SGBV as a weapon of war has come to light more recently, due to the atrocities in Rwanda and the former Yugoslavia. ${ }^{8}$
Systematic rape may be used as a weapon for ethnic cleansing. Women less than twenty-five years of age, and of a particular ethnic background, are thought to be at greater risk for SGBV, as are women of low socio-economic status who live in circumstances with poor security. SGBV leads to the spread of HIV and STIs; can lead to genital, anal, and other physical injuries and to unwanted pregnancies; and accounts for a variety of psychosocial difficulties for women. ${ }^{9}$

Domestic violence plagues many women worldwide and this form of violence may begin or escalate during pregnancy, or patterns of abuse may be altered with more injuries to the abdominal area attempted. ${ }^{10}$ Physical and psychological torture has been extensively reported to occur to both women and men and takes many forms. ${ }^{11}$ All organ systems may be affected and in particular the musculoskeletal and nervous systems. Post-traumatic stress disorder, anxiety, depression, somatization, and other psychological effects are common sequelae. Refugee men may be subject to general physical torture while refugee women are subject to sexual abuse.

Female genital mutilation (FGM) affects one hundred million girls and women worldwide and is considered by many to be a form of SGBV. It is performed in twenty-six African countries and by groups in Oman, South Yemen, the United Arab Emirates, Indonesia, and Malaysia. ${ }^{12}$ In addition to the chronic health effects of these procedures, including urinary tract infections, painful menstruation, and scarring, difficulties can arise in passing the infant through the birth canal and there is increased risk of uterine rupture. ${ }^{13}$

It is generally assumed that refugee women have poorer pregnancy outcomes than other women, although few data are available to refute or support this claim. It is likely that infant and pregnancy health outcomes such as mortality are poorer in war-affected populations although perhaps no worse than in their own country of origin once restabilization of the country or population occurs. ${ }^{14}$ This may be explained by the relatively greater availability of health care services in refugee camps. There is also a dearth of data on other maternal health outcomes such as morbidity and nutritional status. Safe motherhood is thought to be determined by factors shared by settled populations: socio-economic status, age, education, access to services, and urban vs. rural habitation. ${ }^{15}$ However, what distinguishes migrating refugee women from settled women is their increased exposure to war, SGBV, abuse and torture, and STIs/HIV.

Several reports have considered the needs of refugee women ${ }^{16}$ and the reproductive health care services that they are receiving. ${ }^{17}$ A great deal of effort is now being placed on ensuring that a minimum set of reproductive health services is made available to refugee women in camps. 
Migration and Health in Resettlement Countries

Immigration classifications vary by country, although the concept of the ability to freely return to the country of origin usually distinguishes immigrants, who have that option, from refugees, who do not. The differences in experiences between those in these two broad categories have been reviewed. ${ }^{18}$ When examined together, immigrants are multi-ethnic, their mother tongue and language used vary, and they have a variety of religious traditions, lifestyles, and political alliances. As opposed to refugees, other immigrants choose to resettle. They are motivated to leave their countries and re-establish themselves in a new country in the hope of a better life. Their departures are planned and they are able to return to their countries of origin if they choose. On the other hand, refugees are forced to leave their countries to ensure their survival. Their arrival in the new country is in many respects involuntary and they are not able to return to their countries of origin. Their departures from their homelands are often from violent situations in which they have not been able to put closure to important relationships and they may feel guilty for leaving their families or friends. All immigrants will go through phases of adjustment, although the permanent, forced nature of the refugee migration experience makes their integration into society more difficult. ${ }^{19}$

There is a paucity of systematically collected data on health statistics as they relate to migration history. ${ }^{20}$ Most available reports are of small studies, each with its own objectives, methods, and measurement strategies, dissimilar from the others. One review has summarized some of the apparent trends in health due to migration, specifically migration within the European Union. ${ }^{21}$ The quality of individual studies reviewed, in particular sampling strategies, which might suggest that results are representative of the population under investigation, was not addressed. With this limitation in mind, that review suggested that there are trends towards a rise in tuberculosis, HIV/AIDS, cardiovascular diseases, and certain cancers in immigrants. It also suggested that there is a greater number of avoidable accidental injuries at work and at home. Another study suggested that communicable disease prevalence is high in certain immigrant population groups. ${ }^{22}$ Also reported are difficulties in communication, problematic interpretations of patient symptoms, lack of health-care provider understanding of traditional remedies for common ailments, unemployment, depression, and under-utilization of services. ${ }^{23}$

Psychosocial problems appear to be common and may result from resettlement policies stressing geographical dispersion of migrants to areas where there are few "like" community members in an effort to quickly integrate them into mainstream society. Separation and divorce are repor- ted to be frequent. ${ }^{24}$ Additional family difficulties are said to occur if children are seen to be integrating more quickly than their parents by acquiring the language skills of the new country, resulting in a capacity to more easily function in the new society with a shift in power from the parent to the child.

\section{Refugee Women's Health during Resettlement}

As with studies of migration and health generally, many studies of resettling refugee women's health have also been small, and, for the most part, did not define "refugee" consistently nor did they rely on representative sampling or make a direct comparison between refugee women and their host country counterparts. These limitations preclude drawing conclusions with regard to the prevelance of health concerns within the population of resettling refugee women and their relative importance in comparison to host-country women. They do, however, suggest health issues that should be considered with regard to refugee women. These include: conflicts arising in women concerning control of their own sexuality, ${ }^{25}$ perinatal health, ${ }^{26}$ the reintroduction of FGM, ${ }^{27}$ mental health, ${ }^{28}$ health service needs, occupational health risks, and discrimination.

Many immigrant and refugee women are reported to have difficulty controlling their sexuality. ${ }^{29}$ There is a great deal of confusion with regard to the maintenance of virginity, with family values and those of the new society often clashing. ${ }^{30}$ This can lead to requests for hymenal reconstruction by some women who are expected to be virgins when they marry and must provide evidence of this through blood-stained sheets. Girls may suffer a fear of being put to death if it is determined that they are not virgins. ${ }^{31}$ Women from some African countries are not taught or socialized to say "no" to sexual advances by their husbands. ${ }^{32}$ This stands in stark contrast to many refugee-receiving countries in which a woman may refuse her husband's advances and if he forces himself on her, he can be charged with rape. If women suggest the use of condoms to husbands having extramarital affairs, this can lead to violence by the husbands towards the women. These women risk being abused in their attempts to protect themselves against STIs and unwanted pregnancies. Infertility or sub-fertility is also thought to cause a great number of problems, especially in groups in which fertility gives rise to social standing.

Perinatal health outcomes are cited as an area of concern. ${ }^{33}$ Infants born to migrants from certain countries have been reported to be of lower birthweight and shorter gestational age, and to experience higher perinatal and postneonatal mortality than infants of nationals. Only limited reference has been made to other areas of reproductive 
health. Nutrition, including breastfeeding, was cited as another area of concern. Initiation and continuance of breastfeeding is thought to be decreasing in migrants ${ }^{34}$ and nutritional problems in their children are reported to be common.

FGM is being reintroduced into Europe and North America by certain immigrant communities. The Centers for Disease Control in the U.S., for example, estimates that approximately 168,000 girls and women living in the U.S. in 1990 either had or may have been at risk for FGM. An estimated 48,000 of these were under eighteen and about 75 per cent of these were born in the U.S. ${ }^{35}$

Several mental health issues have been cited as important to resettling refugee women. These include anxiety, depression, somatization, social isolation, and domestic violence. ${ }^{36} \mathrm{~A}$ review of childbearing and women's mental health noted studies reporting psychiatric disorders during pregnancy and postpartum. ${ }^{37}$ In addition to other psychiatric disorders, post-traumatic stress disorder was reported.

Inadequate health services due to language barriers, or inappropriate sex or culture "matching" between the woman and her care provider, have been reported. ${ }^{38}$ General health services delivery issues relevant to resettling refugee women are reported to include: general attitudes toward disease, attitudes towards receiving care by male health care professionals, and religious taboos. ${ }^{39}$

Occupational health issues are another area to consider. Refugee women may be employed in certain types of industry for which they are over-qualified and in which the general health risks are important due partially to poor protection by employers. ${ }^{40}$ Some of the general health issues include repeated movement injuries; eye, lung, and skin exposure to toxic substances; long hours of factory employment followed by long hours of home care; and accidental injury. ${ }^{41}$ Foreign-earned educational credentials, which some refugee women may possess, are an asset to the receiving society in terms of the knowledge base gained. ${ }^{42}$ They can, however, lead to psychological problems in the woman due to her drop in social status when those credentials are not recognized by the receiving society. ${ }^{43}$ Unfamiliar environments may pose very real challenges to resettling refugee women. Even household items such as dishwashers and fireplaces and practices such as usual garbage removal may need to be explained to women. ${ }^{44}$ Discrimination based on colour, physical features, or race is another issue that must be dealt with by many refugee women, ${ }^{45}$ not only in the workplace but in every aspect of their lives. ${ }^{46}$

\section{Summary}

Studies reviewed on resettling refugees suggest health concerns to consider with regard to women's reproductive health; however, they do not provide insight into the extent to which these health concerns prevail across various refugee populations. The studies reviewed were, for the most part, unsystematic and uncritical reviews, published reports, or case reports, which provide insight into the particular situations of certain individuals. Well-conducted population-based studies are required to provide an estimate of the prevalence of reproductive health issues of concern in resettling refugee women and their relative importance when compared to non-refugee host-country counterparts. The literature reviewed thus far suggests that there may be several reproductive health-related factors to consider with regard to resettling refugee women. These are summarized in Figure 1 on the next page.

\section{Research Question}

Are there any differences in reproductive health indicators between refugee or asylum-seeking women in countries of resettlement and their non-refugee counterparts?

\section{Methods}

The methods chosen to answer the research question were based not on an interest in the specifics of a particular refugee group, but rather on an interest in the potential similarities of women's health issues across refugees resettling in various countries worldwide and the extent to which issues suggested in the qualitative literature and in non-representative studies were supported in population-based reports. It was thought that identifying common issues across resettling refugee women might enlighten policy makers in various refugee-receiving countries as to the health issues to be considered in defining immigration policies and in planning for resettlement.

\section{Criteria for Considering Studies for This Review}

Types of studies: original research

Types of participants: refugees and "unspecified" immigrants (i.e., migration history not specified); sample comprising at least 50 per cent women or data provided separately for women

Types of outcomes: any quantitative indicator of physical or mental health or health services use

\section{Search Strategy for Identification of Studies}

Literature was culled from five electronic databases - Medline 1966-2001, CINAHL 1982-2001, HealthStar 1975-2001, PsychInfo 1887-2001, and Sociofile 1963-2001 - 
Figure 1:

Factors Related to the Reproductive Health of Resettling Refugee Women

Migration Factors

- Forced to leave country of origin

-Rural/urban source area

-War in source country

-Camp experience

- History of torture/abuse

-Family separation

-"Like community" in new

country

-Length of time in new country

- Official language ability

-Discrimination experience

- Change in social status

-Legal status in new country
Women's Health

-Family planning

-Post-abortion care

-STI/HIV prevention

-Female genital mutilation

-Sex \& gender-based violence

(including rape)

-Pregnancy \& childbirth history

-Current pregnancy \& childbirth

-Menopause

Bio-psycho-social Factors

-Age

-Education

-Diet

-Nutritional status

-Infectious disease exposure

-Injury

-Social support/isolation

-Problem solving ability

-Employment history \& occupational exposures

-Income history (household \& woman)

-Stress/anxiety

-Stress management

-Depression

-Post-traumatic stress disorder

-Somatization

-Smoking/alcohol/drug use

-Services available/received (Western \& traditional)

-Sex/culture matching with provider

-Current abuse 
after consultation with a university librarian regarding optimal search strategies and database-specific terminology. Selected terms related to refugees, immigrants, multiculturalism/culture were used, producing 183,361 citations. When these terms were combined with "women's health" or related terms, 1,568 citations were identified. This list of citations was reviewed, and relevant abstracts obtained. Abstracts clearly describing studies not meeting inclusion criteria were excluded from further consideration. All remaining full-text articles $(n=193)$ were obtained for review. The specific search strategies applied to each database are detailed in Table 1. Bibliographies of relevant studies were reviewed and additional articles retrieved. Abstracts from the Conference Proceedings of the Reproductive
Health for Refugees Consortium, 2000, were also reviewed. Web sites of multilateral and bilateral agencies that address refugees' concerns and academic centres focusing on refugees were searched for relevant literature. A web search was also conducted using the Google search engine, applying the terms "refugee women" and "reproductive health."

\section{Procedure for Consolidating Studies Identified}

The full text of studies identified from the various sources was reviewed and inclusion criteria were applied to them. Those of refugee women in camps or in transit were removed from further consideration. Remaining studies were subsequently assessed for their methodological quality in terms of providing a population estimate of a health event.

Table 1

Search Methodology in Electronic Databases

\begin{tabular}{|c|c|c|c|c|c|}
\hline $\begin{array}{c}\text { Variable } \\
\text { Search Terms }\end{array}$ & $\begin{array}{c}\text { Medline } \\
1966-2001\end{array}$ & $\begin{array}{c}\text { CINAHL } \\
1982-2001\end{array}$ & $\begin{array}{l}\text { HealthStar } \\
1975-2000\end{array}$ & $\begin{array}{c}\text { PsychINFO }^{1} \\
1887-2001\end{array}$ & $\begin{array}{c}\text { SocioFILE } \\
1963-2001\end{array}$ \\
\hline Refugee $^{\star}$ & $\begin{array}{l}\text { Refugees or } \\
\text { asylum.tw or } \\
\text { refugees\$.tw }\end{array}$ & Exp. Refugees & $\begin{array}{l}\text { Exp. Refugees or } \\
\text { asylum.tw }\end{array}$ & Exp. Refugees & $\begin{array}{l}\text { Exp. Refugees or Asylum } \\
\text { seeker.mp }\end{array}$ \\
\hline Immigrant $^{*}$ & $\begin{array}{l}\text { Emigration \& } \\
\text { Immigration or } \\
\text { population dynamics }\end{array}$ & $\begin{array}{l}\text { Exp. Immigratns/ or } \\
\text { immigrants, } \\
\text { illegal.mp or } \\
\text { transient.mp }\end{array}$ & $\begin{array}{l}\text { Exp. Emigration \& } \\
\text { Immigration }\end{array}$ & $\begin{array}{l}\text { Exp. Immigrants } \\
\text { Exp. Immigration }\end{array}$ & $\begin{array}{l}\text { Exp. Immigrants } \\
\text { Exp. Migrants } \\
\text { Exp. Emigration }\end{array}$ \\
\hline Multicultural $^{*}$ & $\begin{array}{l}\text { Exp. Cultural } \\
\text { diversity or exp. } \\
\text { Ethnic groups or } \\
\text { culture }\end{array}$ & $\begin{array}{l}\text { Exp. Cultural } \\
\text { diversity/ or exp. } \\
\text { ethnic groups/ }\end{array}$ & $\begin{array}{l}\text { Exp. Cross-cultural } \\
\text { comparison/ or exp. } \\
\text { Cultural diversity/ or } \\
\text { ethnic groups.mp }\end{array}$ & $\begin{array}{l}\text { Multiculturalism } \\
\text { Cultural Sensitivity } \\
\text { Cross Cultural Diff. } \\
\text { Minority Groups }\end{array}$ & $\begin{array}{l}\text { Exp. Culture } \\
\text { Exp. Cultural Contrast }\end{array}$ \\
\hline Women's Health* & Exp. women's health ${ }^{5}$ & Exp. women's health & $\begin{array}{l}\text { Exp. Women's } \\
\text { health }^{6}\end{array}$ & $\begin{array}{l}\text { Exp. Health and Exp. } \\
\text { Human Female }\end{array}$ & $\begin{array}{l}\text { Women's health care }=111 \\
\text { Exp. Health/ and exp. } \\
\text { Women's health care }=108 \\
\text { Female }=16106\end{array}$ \\
\hline Total & $\begin{array}{l}C=538=967^{1} \\
\text { kept }=88\end{array}$ & $\mathrm{C}=339 ; \mathrm{kept}=50$ & $C=160 ; \mathrm{kept}=23$ & $\mathrm{C}=68 ;$ kept $=23$ & $\mathrm{C}=463 ;$ kept $=9$ \\
\hline
\end{tabular}

Number of "combination" articles $=1568$

Number of "kept" articles $=193$
* And related terms

Exp. $=$ explode term

.tw $=$ text word

$\mathrm{C}=$ search term combined with women's health or related term

Kept $=$ the studies that were kept from the search

1 No pertinent data from 1887 to 1967.

2 Difficult search; "women" and "women's health" were not relevant search terms; "female" as a search term was vague; none of the searches produced relevant articles.

3 Combined all search terms with "women's health care" and with "female."

4 Term is not used before 1984 .

5 "Women's health" is not a searchable term from 1966-1974, 1975-1986. Exploded "health" and exploded "women." No relevant articles were found

6 "Women's health" was not a strong search term from 1975-1991. "Health/or women's health" was used as a search term.

7 Number of hits found when combining "health" and "exp. Cultural diversity," etc. from 1966 to 1986. 
Methodological quality was determined through assessment of the likely presence or absence of biases that might have affected the internal validity of the studies' results. These included assessments of (1) the adequacy of the sampling strategy and completeness of follow-up and (2) appropriateness of the measurement strategy including the use of reliable and valid questionnaires administered in appropriate language and cultural contexts.

Based on this assessment, studies were graded as "low quality" in terms of providing a population estimate of a health event if the sampling strategy was not representative of the population of interest or if it was not described, and if the measurement strategy employed questionnaires or other measurement strategies with no reliability or validity data to support their use in that population or was not described. They were graded as being of "moderate quality" if the sampling strategy was not clearly representative of the population of interest but employed a quasi-representative approach and if the measurement strategy included some consideration of cultural/language variations in obtaining needed data or if there was representative sampling with weak measurement strategies or vice versa. Studies were considered to be of "high quality" if the sampling strategy was clearly representative and if measurement strategies employed were known to be reliable and valid for the population under study. Studies were grouped into low, medium, and high quality for purposes of discussion; no statistical analyses were used to combine the data due to the large variation in health events selected for measure in each of the studies.

As the scoring scheme suggests, those studies not deemed to be of high quality had important limitations, suggesting that health event estimates provided by them might lead to inaccurate conclusions regarding the health status of refugee and other women. Only data from high quality studies, therefore, were used in attempting to answer the research question.

\section{Results}

The various search strategies employed resulted in a large number of citations potentially eligible for inclusion $(\mathrm{n}=1,568)$ and application of initial inclusion criteria resulted in retrieval of a large number of articles $(n=193)$. Once reviewed, a total of forty-one studies met the "high quality" criteria; twenty-three met moderate quality criteria, and twenty-five were found to be of poor quality.

Fourteen of the high-quality studies looked at refugees exclusively, nine of which focused on reproductive health indicators. ${ }^{47}$ The remaining twenty-seven studies included "unspecified" immigrants, nineteen of which focused on reproductive health indicators and eight of which focused on other health indicators.

Of the fourteen "high quality" studies on resettling refugee women, eight were published in the $1980 \mathrm{~s},{ }^{48}$ five in the $1990 \mathrm{~s},{ }^{49}$ and one in $2000 .^{50}$ Of the fourteen, twelve were conducted with Indochinese refugees, including Khmer, Vietnamese, Laotian, Cambodian (Kampuchean), Chinese-Vietnamese, and Thai. ${ }^{51}$ Eleven of the twelve were conducted in the United States, one in Australia. ${ }^{52}$ The twelve studies taken together shed some light on the health status of Indochinese refugee women in industrialized resettlement countries. Eight of the studies examined reproductive health and four, mental health. Five of the reproductive health studies made some comparison to the resettlement population. ${ }^{53}$ These comparisons revealed that Indochinese refugee women have higher fertility rates ${ }^{54}$ and higher rates of low birthweight infants, ${ }^{55}$ but lower infant mortality rates $^{56}$ when compared with host country populations. More recent arrivals (e.g., in the resettlement country for less than three months) appeared to have the highest levels of fertility ${ }^{57}$ and highest rates of low birthweight infants. ${ }^{58}$ Other factors found to have affected reproductive health included greater parity, older mothers, shorter interpregnancy intervals, inadequate utilization of prenatal care, ${ }^{59}$ previous adverse outcomes, ${ }^{60}$ and limited education. ${ }^{61}$ Moreover, the number of children born prior to arrival in the resettlement country, the number of years married, and the level of economic and cultural adaptation were all shown to be associated with decreased fertility, whereas aspects of migration history (e.g., time spent in refugee camp) were associated with increased fertility.

The three studies of Indochinese refugees that do not make comparisons to the resettlement population suggest that: refugee women from a rural background have higher fertility levels than those of women in urban areas; ${ }^{62}$ those in resettlement countries for shorter periods present at greater risk, lacking prenatal care, having more infants of low birthweight and more pregnancy complications; ${ }^{63}$ and a high number of refugee women are infected with intestinal parasites and other infections. ${ }^{64}$

The four studies on Indochinese refugee women focusing on mental health show that a number of these women suffer from somatization, ${ }^{65}$ post-traumatic stress disorder, ${ }^{66}$ depression, ${ }^{67}$ and psychological distress. ${ }^{68}$ One of these studies compared refugees to immigrants and found that somatization was higher in refugees. ${ }^{69}$ Associated with mental illnesses were the following factors: low income, ${ }^{70}$ low levels of acculturation, ${ }^{71}$ exposure to violent/traumatic events, ${ }^{72}$ lengthy time spent in a refugee camp, and older age. $^{73}$ 
The two studies that do not consider Indochinese refugee women look at Bosnian women ${ }^{74}$ and refugee women from Eastern Europe, the former Soviet Union, the Middle East, and Africa ${ }^{75}$ and examine these populations resettling in Sweden and Greece respectively. Results suggest that Bosnian women have poorer overall health than Swedish women, namely, low quality of life as measured by poor appetite, memory loss, little leisure time, and low levels of mental wellness as evidenced by low energy, patience, sleep, mood swings, and more physical symptoms. Refugee women in Greece, when compared to indigenous Greek women, were found to have similar rates of low birthweight and pre-term delivery.

The nineteen studies which focus on the reproductive health of "unspecified" immigrant women defined their population as foreign-born without specifying immigrant status. They are included in this report because of a paucity of evidence specific to refugee women. Two studies indicate that immigrant status was measured, but do not present results based on status differences. ${ }^{76}$

Unlike the fourteen studies discussed above, these nineteen studies were conducted in a wide range of ethnic populations. Eleven included all immigrants in their study (i.e., anyone born outside of the host country) ${ }^{77}$ and/or described the population by source continent or race. ${ }^{78}$ The remaining eight studies looked at specific ethnic populations including Mexicans or Puerto Ricans; ${ }^{79}$ Turks, Filipinos, or Vietnamese; ${ }^{80}$ and Ethiopians. ${ }^{81}$ Study settings also varied, with nine of the studies having taken place in the U.S., five in Canada, four in Australia, and one in England.

The results of these nineteen studies suggest overall that foreign-born women experience the same risk, or better birth outcomes in terms of birthweight and/or incidence of pre-term births and/or rate of infant mortality, ${ }^{82}$ and these positive outcomes progressively worsen as time in the receiving country lengthens and/or they become more acculturated. ${ }^{83}$ Two studies found foreign-born women to have a significant rate of low birthweight infants, ${ }^{84}$ while two other studies completely contradicted the above findings, contending that foreign-born women have worse birth outcomes, including higher rates of stillbirths, of peri/post-natal death ${ }^{85}$ and a higher incidence of low birthweight infants. ${ }^{86}$

As in the refugee-specific studies, fertility rates were found to be high in the "foreign-born" population and higher for those with shorter periods of time in resettlement countries. ${ }^{87}$ Other results included: dissatisfaction with prenatal care ${ }^{88}$ reduced prenatal care (fewer than three prenatal visits) associated with a lack of insurance benefits (irrespective of citizenship); ${ }^{89}$ infant care behaviours that vary with number of years since immigration; $;^{90}$ and an increased rate of premarital childbearing amongst immigrant Puerto Rican women when compared to women in their homeland. ${ }^{91}$

The remaining eight high-quality studies which focus on other health indicators do not differentiate refugee women from immigrants and also present results on the "foreign born" as a whole. Three of these studies looked at psychological illness in immigrants and found them to suffer from somatization ${ }^{92}$ and psychological distress. ${ }^{93}$ Psychological distress is shown to be associated with low sense of coherence, poor sense of control, economic difficulties, trauma and/or violence experienced and/or living, ${ }^{94}$ and numerous relocations. ${ }^{95}$ Results of these studies also indicate that immigrants are healthier than the host population in terms of chronic illnesses, life expectancy, and disability and dependency, with immigrants in host countries for the shortest time being the healthiest. ${ }^{96}$

\section{Discussion}

In this systematic review of refugee women's reproductive health, studies of high quality were identified which provide data on population estimates of a narrow range of health events, and these largely in Indochinese refugee women resettling in the U.S. Although there is a great deal of literature on refugees, and refugee women's reproductive health is taking on added importance due to massive movements of people across continents, few data are available to inform immigration health policy in this area. Little has been published on the effect of refugee versus non-refugee migration history on women's health outcomes. In fact, only six studies of high quality comparing reproductive health effects of migration history were identified in this search of five electronic databases and several web sites. The current study adds to the existing body of literature on resettling refugee women's health by highlighting the increased risk, over U.S. nationals, for resettling Indochinese refugees to give birth to low birthweight infants and for them to experience somatization. This review also highlights the lack of clarity employed in published literature in defining study populations by immigration status, migration history, and sex. Extremely few high-quality population-based data are available to support the conclusions of smaller reports described in other literature and represented in Figure 1. This systematic review suggests that there is extremely little evidence available upon which policy and clinical decisions related to the reproductive health of refugee women can be made given the paucity of high quality population-based data.

\section{Limitations}

The results of this study are based on the use of electronic databases, which are searched using keywords input by a 
librarian. It is possible that the keywords used to describe a given article when creating the database and those used for this study could have differed. Further, non-English language keywords would not have been identified in this search. Extensive consultation with a university librarian and additional searching of citations of literature obtained in the initial search were methods applied to reduce the possibility of missing key studies. Studies that have not been published were not included in this review because no such studies were identified from the non-database searches.

\section{Clinical/Policy Implications}

The results of this study indicate that health-related indicators identified in non-population-based studies of refugee women are generally not supported in the high-quality population-based studies currently available with the exception of Indochinese refugee women resettling in the U.S. In that population, care should be taken to ensure adequate assessment for potentially giving birth to low birthweight infants and for the presence of somatization, since both of these health indicators occur more frequently in this population group than in the non-refugee group.

Other factors identified in non-population-based studies were not confirmed in high-quality population-based studies but likely need to be considered in clinical care until they have been ruled out as having been idiosyncratic to a particular subset of refugee women. A thorough clinical assessment should include bio-psycho-social factors, including screening for tuberculosis, intestinal parasites, experience of malaria during pregnancy, and changes in socioeconomic status. Written translations of patient instructions need to be made available to improve comprehension. Risk factors for torture should be assessed including refugee or political asylum-seeking status, immigrant from totalitarian regime, civil war in country of origin, residence in refugee camp, prisoner of war, multiple family members deceased due to trauma, history of arrest or detention, and leadership in anti-government organizations. ${ }^{97}$

Professionals need to affirm that all forms of SGBV are unacceptable in all forums available to them, especially policy forums. Professional bodies need to publicly defend health professionals detained in the performance of their duties and in the maintenance of ethical standards.98 Legislation to prevent FGM needs to be put forward and supported.

\section{Research Implications}

The background literature presented suggests that there are several indicators of health to be explored on a population level to determine the extent to which reports of health problems in a few individual women is, or is not, a widespread problem requiring greater investment in human and financial resources. Several of the issues to be examined are difficult, although not impossible, to address on a population level due to their delicate nature, histories of SGBV and spousal abuse being among them. However, these and others do require confirmation on a larger representative population. Having determined the extent of the problem, implementing and evaluating solutions to them will be required. The weaknesses of several of the studies attempting to provide population estimates must be avoided. These include non-representative sampling strategies and use of culturally inappropriate approaches to obtain needed data. A wide body of literature on translation theory can be tapped for appropriate methodology.

\section{Conclusion}

The results of this systematic review of refugee women's reproductive health suggest there are a woefully inadequate number of studies directly comparing the health events experienced by resettling refugee women to those of their non-refugee counterparts. This paucity of data prohibits planners and policy makers from making informed decisions regarding the distribution of resources. Results further show that, of a large number of factors suggested by other literature to be important, none have been confirmed in high-quality population-based studies of refugee women from a wide variety of backgrounds. There is an urgent need for more studies examining refugee women specifically. In doing so, better definitions of immigration status should be used, optimal translation procedures and culturally sensitive methodology should be exploited, and sampling of populations should be done in a representative fashion.

\section{Notes}

1. UNHCR, "Who Is a Refugee?," online: $<$ http://www.unhcr.ch $>$.

2. Ibid.

3. P. Thonneau, J. Gratton, and G. Desrosiers, "Health Profile of Applicants for Refugee Status (Admitted into Quebec between August 1985 and April 1986)," Canadian Journal of Public Health 81, no. 3 (1990): 182-86; O.S. Miettinen, "The Need for Randomization in the Study of Intended Effects," Statistics in Medicine 2 (1983): 267-71; J. Jones, "Asylum Seekers in UK Receive Poor Health Care,” BMJ 320 (2000): 1492; Y. Fassil, "Looking after the Health of Refugees," BMJ 321 (2000): 59.

4. R. Neugebauer, "Editorial: The Uses of Psychosocial Epidemiology in Promoting Refugee Health," American Journal of Public Health 87, no. 5 (1997): 726-28.

5. National Forum on Health, Canada Health Action: Building on the Legacy (Health Canada,1997).

6. T. McGinn, "Reproductive Health of War-Affected Populations: What Do We Know?," International Family Planning Perspectives 26, no. 4 (2000): 174-80.

7. Ibid. 
8. Center for Reproductive Law and Policy, Reproductive Freedom and Human Rights: Rape and Forced Pregnancy in War and Conflict Situations (Center for Reproductive Law and Policy, 1996); C.A. Palmer and A.B. Zwi, "Women, Health and Humanitarian Aid in Conflict," Disasters 22, no. 3 (1998): 236-49.

9. Center for Reproductive Law and Policy.

10. E. Schmuel and J.G. Schenker, "Violence against Women: The Physician's Role," European Journal of Obstetrics, Gynecology, \& Reproductive Biology 80, no. 2 (1998): 239-45.

11. H.M. Weinstein, L. Dansky, and V. Iacopino, "Torture and War Trauma Survivors in Primary Care Practice," Western Journal of Medicine 165, no. 3 (1996): 112-18.

12. W.K. Jones et al., "Female Genital Mutilation. Female Circumcision. Who Is at Risk in the U.S.?," Public Health Reports 112, no. 5 (1997): 368-77; C. Retzlaff, "Female Genital Mutilation: Not Just 'Over There'," Journal of the International Association of Physicians in AIDS Care 5, no. 5 (1999): 28-37.

13. Anonymous, "A Traditional Practice That Threatens Health-Female Circumcision," WHO Chronicle 40, no. 1 (1986): 31-36; E. Weir, "Female Genital Mutilation," Canadian Medical Association Journal 162 (2000): 1344-45; Schmuel.

14. McGinn.

15. Ibid.

16. A. Craig, "Birth Spacing and Health Care for Refugee Women," Refugees Magazine, no. 95 "International Year of the Family” (UNHCR Publications, 1994).

17. H. Courtney, "Spacing Children, Preventing AIDS," UNHCR Publications - Refugees Magazine, no. 100, "Refugee Women" (1995); R. Marshall, "Refugees, Feminine Plural," UNHCR Publications - Refugees Magazine, no. 100, "Refugee Women" (1995).

18. S. Gravel and A. Battaglini, Culture, santé et ethnicité: vers une santé publique pluraliste (Montreal: Régie Régionale de la Santé et des Services Sociaux, 2000).

19. J. Sundquist et al., "Impact of Ethnicity, Violence and Acculturation on Displaced Migrants: Psychological Distress and Psychosomatic Complaints among Refugees in Sweden," Journal of Nervous \& Mental Disease 188, no. 6 (2000): 357-65; D. Jones and P.S. Gill, "Refugees and Primary Care: Tackling the Inequalities," BMJ 317 (1998): 1444-46.

20. M. Carballo, J.J. Divino, and D. Zeric, "Migration and Health in the European Union," Tropical Medicine \& International Health 3, no. 12 (1998): 936-44; R. Adair and O. Nwaneri, "Communicable Disease in African Immigrants in Minneapolis," Archives of Internal Medicine 159, no. 1 (1999): 83-85.

21. Carballo.

22. Adair.

23. K. Downs, J. Bernstein, and T. Marchese, "Providing Culturally Competent Primary Care for Immigrant and Refugee Women: A Cambodian Case Study," Journal of Nurse-Midwifery 42, no. 6 (1997): 499-508; H.M. Bauer et al., "Barriers to Health Care for Abused Latina and Asian Immigrant Wo- men," Journal of Health Care for the Poor \& Underserved 11, no. 1 (2000): 33-44.

24. C.B. Keely, "The Resettlement of Women and Children Refugees," Migration World 20, no. 4 (1992): 14-18.

25. G.P. Simms, "Aspects of Women's Health from a Minority/Diversity Perspective," available from <www.hc-sc.gc.ca/ canusa/papers/canada/english/minority.htm>; W.M. Huisman, "Trans-Cultural Medicine," Curare 15 (1998): 21-34.

26. Carballo; L. Manderson and M. Mathews, "Vietnamese Attitudes towards Maternal and Infant Health," Medical Journal of Australia 1, no. 2 (1981): 69-720.

27. Retzlaff.

28. C.M. Gannage, "The Health and Safety Concerns of Immigrant Women Workers in the Toronto Sportswear Industry," International Journal of Health Services 29, no. 2 (1999): 409-29.

29. Simms.

30. Huisman.

31. Ibid.

32. Simms.

33. Carballo.

34. Manderson.

35. Retzlaff.

36. P. Allotey, "Travelling with 'Excess Baggage': Health Problems of Refugee Women in Western Australia," Women \& Health 28, no. 1 (1998): 63-81.

37. P. Zelkowitz, "Childbearing and Women's Mental Health," Transcultural Psychiatric Research Review 33, no. 4 (1996): 391-413.

38. Allotey; Simms; Huisman.

39. Huisman.

40. Gannage.

41. Ibid.

42. Simms.

43. Gannage.

44. Simms.

45. Ibid.

46. Gannage.

47. J.M. Davis et al., "Pregnancy Outcomes of Indochinese Refugees, Santa Clara County, California," American Journal of Public Health 72, no. 7 (1982): 742-44; P. Gann, L. Nghiem, and S. Warner, "Pregnancy Characteristics and Outcomes of Cambodian Refugees," American Journal of Public Health 79, no. 9 (1989): 1251-57; D.D. Hopkins and N.G. Clarke, "Indochinese Refugee Fertility Rates and Pregnancy Risk Factors, Oregon," American Journal of Public Health 73, no. 11 (1983): 1307-09; A. Malamitsi-Puchner et al., "Preterm Delivery and Low Birthweight among Refugees in Greece," Paediatric and Perinatal Epidemiology 8 (1994): 384-90; N.S. Roberts et al., "Intestinal Parasites and Other Infections during Pregnancy in Southeast Asian Refugees," The Journal of Reproductive Medicine 30, no. 10 (1985): 720-25; R.G. Rumbaut, "Fertility and Adaptation: Indochinese Refugees in the United States," International Migration Review 20, no. 2 (1986): 428-66; B.G. Ward, B.R. Pridmore, and L.W. Cox, "Vietnamese Refugees 
in Adelaide: An Obstetric Analysis," Medical Journal of Australia 1, no. 2 (1981): 72-75; J.R. Weeks et al., "High Fertility among Indochinese Refugees," Public Health Reports 104, no. 2 (1989): 143-50; J.R. Weeks, "Infant Mortality among Ethnic Immigrant Groups," Social Science \& Medicine 33, no. 3 (2000): 327-34.

48. E.H.B. Lin, W.B. Carter, and A.M. Kleinman, "An Exploration of Somatization among Asian Refugees and Immigrants in Primary Care," American Journal of Public Health 75, no. 11 (1985): 1080-84; Hopkins; Rumbaut, "Fertility and Adaptation: Indochinese Refugees in the United States;" Ward; Weeks, "High Fertility among Indochinese Refugees;" Davis; Gann; Roberts.

49. S.M. Berthold, "The Effects of Exposure to Community Violence on Khmer Refugee Adolescents," Journal of Traumatic Stress 12, no. 3 (1999): 455-71; W.H. Sack et al., "The Khmer Adolescent Project. I. Epidemiologic Findings in Two Generations of Cambodian Refugees," Journal of Nervous \& Mental Disease 182, no. 7 (1994): 387-95; J. Sundquist, A. BehmenVincevic, and S.E. Johansson, "Poor Quality of Life and Health in Young to Middle Aged Bosnian Female War Refugees: A Population-Based Study," Public Health 112, no. 1 (1998): 21-26; R.C. Chung and M. Kagawa-Singer, "Predictors of Psychological Distress among Southeast Asian Refugees," Social Science \& Medicine 36, no. 5 (1993): 631-39; Malamitsi-Puchner. 50. Weeks, "Infant Mortality among Ethnic Immigrant Groups."

51. Lin; Berthold; Hopkins; Rumbaut, "Fertility and Adaptation: Indochinese Refugees in the United States;" Sack; Ward; Weeks, "High Fertility among Indochinese Refugees;" Weeks, "Infant Mortality among Ethnic Immigrant Groups;" Chung; Davis; Gann; Roberts.

52. Ward.

53. Hopkins; Rumbaut, "Fertility and Adaptation: Indochinese Refugees in the United States;" Ward; Gann; Weeks, "Infant Mortality among Ethnic Immigrant Groups."

54. Hopkins; Rumbaut, "Fertility and Adaptation: Indochinese Refugees in the United States."

55. Hopkins; Ward.

56. Weeks, "Infant Mortality among Ethnic Immigrant Groups."

57. Rumbaut, "Fertility and Adaptation: Indochinese Refugees in the United States."

58. Hopkins.

59. Gann; Hopkins.

60. Gann.

61. Hopkins.

62. Weeks, "High Fertility among Indochinese Refugees."

63. Davis.

64. Roberts

65. Lin.

66. Sack; Berthold.

67. Sack.

68. Chung.

69. Lin.

70. Lin; Chung.

71. Ibid.
72. Berthold; Chung.

73. Chung.

74. Sundquist, "Poor Quality of Life and Health in Young to Middle Aged Bosnian Female War Refugees: A PopulationBased Study."

75. Malamitsi-Puchner.

76. N.C. Edwards and J.F. Boivin, "Ethnocultural Predictors of Postpartum Infant-Care Behaviours among Immigrants in Canada," Ethnicity \& Health 2, no. 3 (1997): 163-176; R. Rumbaut, "Unraveling a Public Health Enigma: Why Do Immigrants Experience Superior Perinatal Health Outcomes," Research in the Sociology of Health Care 13B (1996): 337-91.

77. K. Ford, "Duration of Residence in the United States and the Fertility of U.S. Immigrants," International Migration Review 24, no. 1 (1987): 34-68; H. Doucet, M. Baumgarten, and C. Infante Rivard, "Risk of Low Birthweight and Prematurity among Foreign-Born Mothers," Canadian Journal of Public Health 83, no. 3 (1992): 192-95; Edwards; I. Hyman, "The Effect of Acculturation Low Birth Weight in Immigrant Women," Canadian Journal of Public Health 87, no. 3 (1998): 158-62; J.C. Kleinman, L.A. Fingerhut, and K. Prager, "Differences in Infant Mortality by Race, Nativity Status, and Other Maternal Characteristics," American Journal of Diseases of Children 145, no. 2 (1991): 194-99; E. Ng and F. Nault, "Fertility Among Recent Immigrant Women to Canada,1991: An Examination of the Disruption Hypothesis," International Migration 35, no. 4 (1997): 549-79; B. Ram and V. George, "Immigrant fertility patterns in Canada, 1961-1986," International Migration Review (1989), 413-25; G.K. Singh and S.M. $\mathrm{Yu}$, "Adverse Pregnancy Outcomes: Differences Between USand Foreign-Born Women in Major US Racial and Ethnic Groups," American Journal of Public Health 86, no. 6 (1996): 837-43; Rumbaut, "Unraveling a Public Health Enigma: Why Do Immigrants Experience Superior Perinatal Health Outcomes,".

78. Ford; Doucet; Edwards; Hyman; Kleinman; Ng; Ram; Singh; Rumbaut, "Unraveling a Public Health Enigma: Why Do Immigrants Experience Superior Perinatal Health Outcomes;" J.W. Jr Collins and D.K. Shay, "Prevalence of Low Birth Weight among Hispanic Infants with United States-Born and Foreign-Born Mothers: The Effect of Urban Poverty," American Journal of Epidemiology 139, no. 2 (1994): 184-92; W.D. Dolton, "The Health and Welfare of the Immigrant," Royal Society of Health Journal 86, no. 1 (1966): 22-27.

79. A. Cervantes, L. Keith, and G. Wyshak, "Adverse Birth Outcomes among Native-Born and Immigrant Women: Replicating National Evidence Regarding Mexicans at the Local Level," Maternal \& Child Health Journal 3, no. 2 (1999): 99-109; I. Kalofonos and L.A. Palinkas, "Barriers to Prenatal Care for Mexican and Mexican American Women," Journal of Gender, Culture, \& Health, 4, no. 2 (1999): 135-52; N.S. Landale and S.M. Hauan, "Migration and Premarital Childbearing Among Puerto Rican Women," Demography 33, no. 4 (1996): 429-42.

80. J. Mitchell and D. Mackerras, "The Traditional Humoral Food Habits of Pregnant Vietnamese-Australian Women and Their 
Effect on Birth Weight," Australian Journal of Public Health 19, no. 6 (1995): 629-33; O.A. Henry et al., "Obstetric and Birthweight Differences between Vietnam-Born and AustralianBorn Women," Medical Journal of Australia 156, no. 5 (1992): 321-24; R. Small et al., "Shared Antenatal Care Fails to Rate Well With Women of Non-English-Speaking Backgrounds," Medical Journal of Australia 168, no. 1 (1998): 15-18; J. Yelland et al., "Support, Sensitivity, Satisfaction: Filipino, Turkish and Vietnamese Women's Experiences of Postnatal Hospital Stay," Midwifery 14, no. 3 (1998): 144-54.

81. H. Wasse, V.L. Holt, and J.R. Daling, "Pregnancy Risk Factors and Birth Outcomes in Washington State: A Comparison of Ethiopian-Born and US-Born Women," American Journal of Public Health 84, no. 9 (1994): 1505-07.

82. Cervantes; Collins; Hyman; Rumbaut, "Unraveling a Public Health Enigma: Why Do Immigrants Experience Superior Perinatal Health Outcomes;" Singh; Doucet; Wasse; Kleinman; Kalofonos.

83. Rumbaut, "Unraveling a Public Health Enigma: Why Do Immigrants Experience Superior Perinatal Health Outcomes;" Hyman.

84. Mitchell; Kleinman.

85. Dolton.

86. Henry.

87. Dolton; Ford; Ram; Ng.

88. Small; Yelland.

89. Kalofonos.

90. Edwards.

91. Landale.

92. M. Ritsner et al., "Somatization in an Immigrant Population in Israel: A Community Survey of Prevalence, Risk Factors, and Help-Seeking Behavior," American Journal of Psychiatry 157, no. 3 (2000): 385-92.

93. Sundquist, "Impact of Ethnicity, Violence and Acculturation on Displaced Migrants: Psychological Distress and Psychosomatic Complaints among Refugees in Sweden;" L.M. Johansson et al., "Immigration, Moving House and Psychiatric Admissions," Acta Psychiatrica Scandinavica 98 (1998): 105-11.

94. Sundquist, "Impact of Ethnicity, Violence and Acculturation on Displaced Migrants: Psychological Distress and Psychosomatic Complaints among Refugees in Sweden.”

95. Johansson.

96. J. Chen, E. Ng, and R. Wilkins, "The Health of Canada's Immigrants in 1994-95," Health Reports 7, no. 4 (1996): 33-45; J. Sundquist and S.E. Johansson, "Long-Term Illness among Indigenous and Foreign-Born People in Sweden," Social Science \& Medicine 44, no. 2 (1997): 189-98; J. Chen, R. Wilkins, and E. Ng, "Health Expectancy by Immigrant Status, 1986 and 1991," Health Reports 8, no. 3 (1996): 29-38.

97. Weinstein.

98. H.J. Geiger and R.M. Cook-Deegan, "The Role of Physicians in Conflicts and Humanitarian Crises. Case Studies from the Field Missions of Physicians for Human Rights, 1988 to 1993," Journal of the American Medical Association 270, no. 5 (1993): 616-20.
Anita J. Gagnon, R.N., M.P.H., Ph.D., is assistant professor at the School of Nursing and in the Department of Obstetrics and Gynecology, McGill University. She is also a nurse scientist at the McGill University Health Centre (MUHC), the Royal Victoria Hospital site. Lisa Merry, R.N., M.Sc., is a research coordinator, McGill University. Cathlyn Robinson, R.N., B.S.N., is a clinical nurse specialist for trauma, McGill University Health Centre (MUHC), Montreal General Hospital site. This study was partially supported through the Fonds de la recherche en santé du Québec (FRSQ), a peer-review funding agency for health research in Quebec, through their award of a research scholarship (career award) to Dr. Gagnon and through the McGill University Faculties of Graduate Studies and of Medicine. 